\title{
Levels of heavy metals in the raw and processed Ethiopian tobacco leaves
}

Girma Regassa ${ }^{1,2}$ and Bhagwan Singh Chandravanshi ${ }^{*}$

\begin{abstract}
Tobacco (Nicotiana tabacum L.) is a commercial plant. Tobacco leaves naturally accumulate and concentrate relatively high levels of heavy metals and particular cadmium in leaves. Tobacco is one of the basic agricultural products, in Ethiopia, with social and economic importance. However, there is no report in the literature on the determination of levels of heavy metals in Ethiopian tobacco leaves. Hence this research is intended to determine the levels of heavy metals in the raw and processed Ethiopian Virginia tobacco leaves. Samples of raw Virginia tobacco leaves were collected from two different regions of Ethiopia (Billate and Shewa Robit). The three processed tobacco samples were collected from National Tobacco Enterprise, Addis Ababa, Ethiopia. The samples were wet-digested using $3 \mathrm{~mL} \mathrm{HNO}_{3}$ (69-72\%) and $3 \mathrm{~mL} \mathrm{HClO} 4$ (70 \%) at $350{ }^{\circ} \mathrm{C}$ for $3.5 \mathrm{~h}$ and concentrations of heavy metals ( $\mathrm{Cd}, \mathrm{Cr}, \mathrm{Cu}, \mathrm{Ni}, \mathrm{Pb}$ and $\mathrm{Zn}$ ) in the samples were determined by flame atomic absorption spectrometer. The mean metals concentrations (in $\mu \mathrm{g} / \mathrm{g}$ dry weight) in the raw Virginia tobacco leaves from Billate and Shewa Robit, respectively, were: $\mathrm{Cu}(4.38,7.30), \mathrm{Zn}(53.7$, 33.2), $\mathrm{Cd}(1.20,1.30), \mathrm{Cr}(\mathrm{ND}, 1.45), \mathrm{Ni}(\mathrm{ND}, 1.90)$. The mean metals concentrations (in $\mu \mathrm{g} / \mathrm{g}$ dry weight) in the processed tobacco from Billate and Shewa Robit, respectively, were: Cu $(9.80,12.8), \mathrm{Ni}(2.35,2.20) \mathrm{Cd}(1.45,1.90), \mathrm{Cr}(1.65,1.75), \mathrm{Zn}$ $(101,83.8)$. The mean metals concentrations (in $\mu \mathrm{g} / \mathrm{g}$ dry weight) in the processed tobacco Nyala (Ethiopian cigarette leaves) were: $\mathrm{Cu}$ (8.95), $\mathrm{Cd}$ (1.55), $\mathrm{Cr}$ (1.62), $\mathrm{Ni}$ (4.70), Zn (79.3). The concentrations of $\mathrm{Cr}$ and $\mathrm{Ni}$ in tobacco leaves from Billate and $\mathrm{Pb}$ in all the tobacco samples were below the detection limits. This study showed that the metal contents of tobacco leaves varied with the geographical origin in which the tobacco plant grows. The metal contents of processed tobacco were higher than the corresponding raw leaves. Pb was not detected in both the raw and processed Ethiopian tobacco leaves.
\end{abstract}

Keywords: Tobacco leaves, Cigarette tobacco leaves, Heavy metals, Nyala, Ethiopia

\section{Background}

Tobacco (Nicotiana tabacum L.) is a commercial plant. Tobacco is one of the basic agricultural products, in Ethiopia, with social and economic importance. Native tobacco ('gaya') has been used for snuffing, chewing and for pipe smoking in many places.

Tobacco is grown for commercial purposes by stateowned farms and by farmers around these farms. The National Tobacco Enterprise has been given the mandate to organize tobacco production and processing in the country. Three main types of commercial tobacco

\footnotetext{
*Correspondence: bscv2006@yahoo.com

1 Department of Chemistry, College of Natural Sciences, Addis Ababa

University, P.O. Box 1176, Addis Ababa, Ethiopia

Full list of author information is available at the end of the article
}

are produced in Ethiopia: Virginia, Oriental and Burley. Virginia accounts for a little more than $74 \%$ of the total production, followed by Oriental, $22 \%$, and Burley, $4 \%$ (FAO 1995, 2003). Major cultivation areas are Sidamo, Northern Shoa, and Hararghe. Commercial production is concentrated in Shewa Robit (North Shoa), Billate, Awassa, Wolaita (Sidamo) and in Nura-Era (Hararghe). State farms in these areas produce about 500-900 MT of cured leaves annually from about 2000 hectares of land (FAO 1995, 2003).

UNODC report (Gebre Selassie and Gebre 1996) reveals that in Ethiopia peoples commonly use khat, tobacco, and alcohol, which have a share of 48.2, 29.9 and $18.9 \%$, respectively, of all type of drugs. This clearly shows that tobacco made significant contribution as a drug in Ethiopia. Commonly Virginia, Oriental and

\section{黛 Springer}

(C) 2016 Regassa and Chandravanshi. This article is distributed under the terms of the Creative Commons Attribution 4.0 International License (http://creativecommons.org/licenses/by/4.0/), which permits unrestricted use, distribution, and reproduction in any medium, provided you give appropriate credit to the original author(s) and the source, provide a link to the Creative Commons license, and indicate if changes were made. 
Burley are commercial tobacco species used for making cigarettes in Ethiopia.

Tobacco (Nicotiana tabacum L.) is a commercial plant. Tobacco leaves are used for cigarette production and chewing. It naturally accumulates and concentrates relatively high levels of heavy metals and particular cadmium in leaves (Kaličanin and Velimirović 2012; Ajab et al. 2014). Cadmium is a non-essential to both plant and human. It is highly toxic and gets accumulated by tobacco plants. Cadmium is transferred to human being through cigarette smoking (Jarup et al. 1998; Nordberg et al. 2007; Verma et al. 2010). Most heavy metals cause a significantly serious damage on human health (Baldwin and Marshall 1999; Smith and Doolittle 1999; Health Canada 1999; Rothwell and Yorkshire 1999; Stojanovic et al. 2004; Sharma and Dubey 2005; Nnorom et al. 2005; Zhang et al. 2005; Lugon-Moulin et al. 2006). Cadmium is associated with bone and kidney diseases and $\mathrm{Pb}$ with neurological disorders (Sharma and Dubey 2005; Nnorom et al. 2005). Excess of $\mathrm{Cu}$ and $\mathrm{Zn}$ are associated with metabolic disorders potentially resulting in death (Stojanovic et al. 2004; Zhang et al. 2005). One of the main sources of toxic metals in our environment is tobacco smoke. Cigarette smoking is a major source of intake of these toxic elements not only to the smoker but also, through passive smoking, to nonsmokers.

The degree of accumulation of heavy metals in the tobacco plant results from a complex interaction between the soil and plant. The degree of accumulation of the metals from the soil depends on the type of soil, the $\mathrm{pH}$ value, the quality of water used for irrigation, the chemical composition of the metal, and the type of tobacco plant (Grant et al. 1998; Golia et al. 2008). The farmers use large amounts of fertilizers and pesticides during the production of tobacco plant. The fertilizers and pesticides usually contain high concentrations of metals and contribute a major degree in the pollution of agricultural soil, as well as plants (Karaivazoglou et al. 2007; Lecours et al. 2012).

The distribution and accumulation of metals in tobacco leaves are the reflection of the mineral composition of the soil and environment in which the tobacco plant grows. Therefore, the actual metals content of tobacco vary considerably according geographic origin, the use of fertilizers with different chemical compositions and other characterizing features such as water for irrigation (Peuarossa et al. 1990; Adeyeye 2005; Lugon-Moulin et al. 2006). The phosphates fertilizers, which are used in tobacco cultivation, contain high concentrations of heavy metals.

Literature survey revealed a large number of report on the determination of two of the most toxic heavy metals (As and $\mathrm{Hg}$ ). Arsenic concentration averaged
$(0.4 \pm 0.6 \mu \mathrm{g} / \mathrm{g})$ in the tobacco samples from Africa, Asia, Europe, South and North America has been determined by inductively coupled plasma-mass spectrometry (Lugon-Moulin et al. 2008). Taebunpakul et al. (2011) have determined total arsenic and arsenic speciation in tobacco products: from tobacco leaf and cigarette smoke by HPLC-ICP-MS. Lazarević et al. (2012) have determined the contents of arsenic in tobacco $(<0.02-2.04 \mu \mathrm{g} / \mathrm{g})$ and cigarettes $(<0.02-0.71 \mu \mathrm{g} / \mathrm{g})$ by electro-thermal atomic absorption spectrometry. Campbell et al. (2014) have determined total inorganic arsenic species $(144-3914 \mu \mathrm{g} / \mathrm{kg})$ in tobacco samples from different origin using HPLC-ICP-MS. Piadé et al. (2015) have determined arsenic levels in tobacco filler and cigarette smoke in a large number of samples worldwide survey and reported median tobacco level for arsenic $237 \mathrm{ng} / \mathrm{g}$ while median mainstream smoke yields for arsenic was $<3.75$, ng/cigarette. Maruyama and Komiya (1973) have determined arsenic and mercury in tobacco leaves by neutron activation analysis. Suzuki et al. (1976) have determined mercury in cigarettes. Chang et al. (2002) reported a rapid method for the determination of mercury in mainstream cigarette smoke by two-stage amalgamation cold vapor atomic absorption spectrometry and the vapor phase mercury in the mainstream smoke was found $7.4 \pm 0.4 \mathrm{ng} /$ cigarette. Zhangyu et al. (2004) have reported levels of mercury in tobacco and tobacco additives by microwave digestion and RP-HPLC followed by on-line column enrichment. Kowalski and Wierciński (2009) have reported mercury contents in cigarette tobacco $(6.48-10.56 \mathrm{ng} / \mathrm{g}, 2.95-10.2 \mathrm{ng} \mathrm{Hg}$ per a single cigarette) determined using mercury analyser.

Several studies have also been reported in the literature on determinations of the levels of heavy metals in the raw and processed tobacco leaves (Kaličanin and Velimirović 2012; Eneji et al. 2013; Ajab et al. 2014) in the different parts of the world using different techniques (Saldivar et al. 1991; Health Canada 1999; Stojanovic et al. 2004; Angelova et al. 2004; Zhang et al. 2005; Nnorom et al. 2005). Some studies have also been carried out in Ethiopia on the levels of essential and non-essential metals in a psychoactive khat leaves (Atlabachew et al. 2010, 2011) as well as in cannabis leaves (Zerihun et al. 2015). A few studies have also been carried out on the levels of nicotine in Ethiopian tobacco leaves (Geto et al. 2012; Kassa et al. 2013; Tassew and Chandravanshi 2015). However, to the best of our knowledge, there is no report in the literature on the levels of heavy metals in Ethiopian tobacco leaves. Hence this research is intended to determine levels of six heavy metals, four of them are toxic $(\mathrm{Cd}, \mathrm{Ni}, \mathrm{Pb}, \mathrm{Cr})$ and two of them are essential $(\mathrm{Cu}, \mathrm{Zn})$, in the raw and processed Ethiopian tobacco leaves by flame atomic absorption spectrometry. Two of the most 
toxic metals (As and $\mathrm{Hg}$ ) were not determined in this study because their determination require highly sensitive and more sophisticated methods and instruments such as neutron activation analysis, cold vapor atomic absorption spectrometry, hydride generation atomic absorption spectrometry, electrothermal atomic absorption spectrometry and inductive couple plasma-mass spectrometry.

\section{Methods}

\section{Instrument and apparatus}

Ceramic pestle and mortar were used for grinding and homogenizing of the raw and processed tobacco leaves. Digital analytical balance (Mettler Toledo, Model AT250, Switzerland) and oven (Digitheat, J.P. Selecta, Spain) were used for weighing and drying the samples, respectively. Quick-fit round bottom flasks $(150 \mathrm{~mL})$ fitted with reflux condenser were used in Kjeldahl apparatus hot plate to digest the samples. Buck Scientific Model 210VGP (East Norwalk, USA) atomic absorption spectrophotometer equipped with deuterium ark background correctors and air- $\mathrm{C}_{2} \mathrm{H}_{2}$ flame was used for the determination of heavy metals.

\section{Chemicals, reagents and standard solutions}

Chemicals and reagents used for the analysis were of analytical reagent grade. $69-72 \% \mathrm{HNO}_{3}$ and $70 \% \mathrm{HClO}_{4}$ (Analar ${ }^{\circledR}, \mathrm{BDH}$, England) were used for digestion of tobacco samples. Stock standard solutions of the metals $(\mathrm{Zn}, \mathrm{Cr}, \mathrm{Cu}, \mathrm{Ni}, \mathrm{Pb}$, and $\mathrm{Cd}), 1000 \mathrm{mg} / \mathrm{L}$ calibration standards (Buck Scientific, USA), prepared as nitrates for each element in $2 \% \mathrm{HNO}_{3}$, were used for the preparation of calibration curves for the determination of metals in the samples. Distilled-deionized water was used for preparation of standard solutions and dilution.

\section{Description of sample sites}

Samples were collected from two-tobacco plantation areas (Shewa Robit and Billate), which account for more than $76 \%$ of total tobacco plant production in Ethiopia and are the only places where Virginia type tobacco is planted. Billate is located in Southern Ethiopia $300 \mathrm{~km}$ from Addis Ababa. Shewa Robit is located in the Northern Ethiopia $215 \mathrm{~km}$ from Addis Ababa. Both places are located in East African Rift Valley. Therefore, the two areas have more or less similar weather conditions and climate. National Tobacco Enterprise, which is the only factory for manufacturing cigarette in Ethiopia, operates a cigarette factory located in Addis Ababa. For this study, Virginia type tobacco was chosen because of its high availability and Nyala (Ethiopian cigarette) type cigarette which is totally manufactured from Virginia type tobacco and accounts more than $89 \%$ of total cigarette production in Ethiopia (Food and Agricultural Organization 1995; National Tobacco Enterprise 2006).

\section{Sample collection}

Depending on the availability of tobacco plant, representative amount of leaves, four leaves per plant staring from bottom to the tips by stalk position, from Billate and Shewa Robit were collected. The collected samples were washed with tap water and rinsed three times with deionized water to make them free of extraneous substances, including soil and dust particles, and foliar spray residues that may influence analytical results (Jones et al. 1991; Maier and Griepink 1995; Iyengar et al. 1998). Another three samples were, processed Virginia whose origin was Billate, Shewa Robit, and Nyala sample. These processed samples, which were ready for use after warping, were prepared in the laboratory of the cigarette factory in exactly the same procedure of Nyala manufacturing by an expert of laboratory in the factory. Both types of samples were sealed in washed, rinsed with distilled-deionized water and dried polyethylene bag and transported to the laboratory where further sample pre-treatments were made. Drying at temperatures under $80{ }^{\circ} \mathrm{C}$ may not remove all combined water and may result in poor homogenization and incorrect analytical results. Drying temperatures above $80{ }^{\circ} \mathrm{C}$ may result in thermal decomposition and reduction in dry weight (Jones et al. 1991). Accordingly, after chopping the samples with plastic knife, all the samples were dried in the oven for $24 \mathrm{~h}$ at $80^{\circ} \mathrm{C}$. The dried samples were well ground by using pestle and mortar and kept in the desiccator until digestion (Nnorom et al. 2005).

\section{Digestion of tobacco samples}

Applying the optimized procedure, $0.5 \mathrm{~g}$ of well-powdered tobacco sample was digested with $3.0 \mathrm{~mL} \mathrm{HNO}_{3}$ (69-72\%) and $3 \mathrm{~mL} \mathrm{HClO}_{4}(70 \%)$ on a micro Kjeldahl digestion apparatus at $350{ }^{\circ} \mathrm{C}$ for $200 \mathrm{~min}$. After cooling, the digest was filtered and diluted to $25 \mathrm{~mL}$ with deionized water. Triplicate digestions were carried out for each sample. The blank solutions were prepared by digesting the mixture of reagents following the same digestion procedure and diluted to $25 \mathrm{~mL}$ with deionized water.

\section{Determination of metals in the tobacco samples}

Four points calibration curves were established by running the standard solutions $(10 \mathrm{mg} / \mathrm{L})$ in flame AAS. Immediately after calibration, the sample solutions were aspirated into the AAS instrument and direct readings of the metal concentrations was recorded. Three replicate determinations were carried out on each sample. The same analytical procedure was employed in the determination of elements in each six digested blank. 


\section{Procedure of spiking}

To confirm the efficiency of developed optimized procedures, spiking experiments in which known volume and concentration of standard solutions, were employed. From the stock solution $(1000 \mathrm{mg} / \mathrm{L})$ an intermediate standard solutions $(10 \mathrm{mg} / \mathrm{L})$ were prepared for all the metals. $13 \mu \mathrm{L}$ of $\mathrm{Cd}, 30 \mu \mathrm{L}$ of $\mathrm{Cr}, \mathrm{Ni}, \mathrm{Pb}, 50 \mu \mathrm{L}$ of $\mathrm{Cu}$, and $70 \mu \mathrm{L}$ of $\mathrm{Zn}$ from $10 \mathrm{mg} / \mathrm{L}$ solutions were added to $0.50 \mathrm{~g}$ tobacco leaves collected from Shewa Robit. The same amounts of solutions were added to processed tobacco sample collected from Billate and Nyala except the volume of $\mathrm{Cd}$ added was increased to $30 \mu \mathrm{L}$ (since the amount $\mathrm{Cd}$ was increased in samples). Then samples were digested and analyzed with the previously optimized procedures.

\section{Results and discussion}

\section{Optimization of digestion procedure}

Concentrated perchloric acid is a powerful oxidizing agent when hot. However, due to the risk of explosion, perchloric acid was used in mixture with nitric acid which serves not only to dilute the perchloric acid but also to ensure the easily oxidizable compounds are broken by reaction with nitric acid first at low temperature before the perchloric acid starts to exert its oxidizing power at $160{ }^{\circ} \mathrm{C}$ (Bock 1979). It is recommended that the sample size should be less than $1 \mathrm{~g}$ for the reason of safety when perchloric acid used for digestion (Bock 1979). Refluxing is compulsory, when a sample is decomposed by open ashing to determine volatile trace elements like Cd (Bock 1979). Using these reagents and $0.5 \mathrm{~g}$ sample different digestion methods were tested and the procedure that produce clear solution, consumed minimal reagent volumes and shorter digestion time, with acceptable sample masses of tobacco samples was selected from the tested alternatives (Bock 1979; Health Canada 1999). Optimization of the digestion procedure involved some changes of parameters such as reagent volume, digestion temperature and digestion time. Based upon above listed criteria, the optimal digestion procedure chosen was the one that fulfilled the stated criteria for complete digestion of $0.5 \mathrm{~g}$ of the dry sample powders, with $3 \mathrm{~mL} \mathrm{HNO}_{3}$ $(69-72 \%)$ and $3 \mathrm{~mL} \mathrm{HClO}_{4}(70 \%)$ for total of 3:30 h. The mixture was heated smoothly for $10 \mathrm{~min}$ by adjusting the temperature to $150{ }^{\circ} \mathrm{C}$. After $10 \mathrm{~min}$ when the evolution of oxides of nitrogen ceased the mixture was heated strongly by adjusting the temperature $350{ }^{\circ} \mathrm{C}$. The procedures that required higher reagent volume, longer digestion time, and which resulted in the formation of turbid digests and colored digest solutions were rejected.

\section{Precision of results}

Precision can be determined by standard deviation, variance, coefficient of variance, relative standard deviation, and range of series measurements (Miller and Miller 2000). In this study the precision of the results were evaluated by the pooled standard deviation and relative standard deviation of the results of triplicate samples and three reading $(n=9)$ obtained for each sample. The result of analysis was reported with corresponding standard deviation at $95 \%$ confidence limit and relative standard deviation. It can be seen that the values of percentage relative standard deviations (\% RSD) are less than $10 \%$ for all the mean concentrations. This shows the precision of the results obtained by this method is good and acceptable.

\section{Validation of optimized procedure}

The efficiency of the optimized procedure was evaluated by analyzing the digests of spiked samples for both raw tobacco leaves and processed tobacco samples (Miller and Miller 2000). The recoveries of metals in the spiked tobacco samples were in the range 88.3-107\%. These values are within the acceptable range for analyses of biological samples such as plants. The results are given in Table 1. Generally, good recoveries were obtained for all the metals. As can be seen from Table 1, percentage recoveries of all metals in all samples are within the range of $100 \pm 10 \%$. Thus, on the average good recoveries were obtained for all elements in all the samples validating that the optimized procedure has good accuracy.

\section{Concentration of metals in the raw tobacco leaves}

Tobacco plant is known to easily absorb heavy metals from soil and accumulate them in the leaves. In this study (Table 2) highest concentration of $\mathrm{Zn}$ was determined in the raw tobacco leaves samples from both sample sites, Billate and Shewa Robit. However, higher average content of $\mathrm{Zn}(53.7 \mu \mathrm{g} / \mathrm{g}$ dry mass) was determined in tobacco leaves from Billate than Shewa Robit $(33.2 \mu \mathrm{g} / \mathrm{g}$ dry mass). Except the amount $\mathrm{Zn}$, all the metals were higher in tobacco leaves from Shewa Robit than Billate. $\mathrm{Pb}$ was found to be lower than the detection limit of the instrument in both the tobacco leaves samples. Ni was determined lower than instrument detection limit in the tobacco leaves from Billate.

The results of this study showed that the metal contents of tobacco leaves varied with the geographical origin in which the tobacco plant grows. Even though there are no industrial activities in both areas of sampling, the natural weathering of rocks, agricultural activities like using fertilizer, herbicide, and water for irrigation could contribute to these concentrations of metals determined in tobacco leaves. A comparison of the metal contents in the tobacco leaves in this study showed that $\mathrm{Zn}$ contents are in higher amounts in the samples compared to the other heavy metals. A relatively higher amount of $\mathrm{Zn}$ in the leaves from both areas could be due to its higher natural 
Table 1 Analytical results obtained for validation of the optimized procedure after spiking with standard solutions

\begin{tabular}{|c|c|c|c|c|c|}
\hline Metal & Type of tobacco sample & $\begin{array}{l}\text { Amount in } \\
\text { unspiked sample }(\mu \mathrm{g} / \mathrm{g})\end{array}$ & Amount added $(\mu \mathrm{g} / \mathrm{g})$ & $\begin{array}{l}\text { Amount in } \\
\text { spiked sample }(\mu \mathrm{g} / \mathrm{g})\end{array}$ & (\%) Recovery \\
\hline \multirow[t]{3}{*}{$\mathrm{Cd}$} & Shewa Robit raw tobacco leaves & $1.30 \pm 0.04$ & 0.26 & $1.54 \pm 0.07$ & $92.3 \pm 6.0$ \\
\hline & Billate processed tobacco leaves & $1.45 \pm 0.023$ & 0.6 & $2.03 \pm 0.03$ & $96.7 \pm 1.9$ \\
\hline & Nyala processed tobacco leaves & $1.55 \pm 0.23$ & 0.6 & $2.11 \pm 0.06$ & $93.3 \pm 3.6$ \\
\hline \multirow[t]{3}{*}{$\mathrm{Cr}$} & Shewa Robit raw tobacco leaves & $1.45 \pm 0.11$ & 0.6 & $1.99 \pm 0.12$ & $90.0 \pm 7.8$ \\
\hline & Billate processed tobacco leaves & $1.65 \pm 0.08$ & 0.6 & $2.23 \pm 0.03$ & $96.7 \pm 1.7$ \\
\hline & Nyala processed tobacco leaves & $1.62 \pm 0.11$ & 0.6 & $2.19 \pm 0.08$ & $95.0 \pm 4.5$ \\
\hline \multirow[t]{3}{*}{$\mathrm{Cu}$} & Shewa Robit raw tobacco leaves & $7.30 \pm 0.19$ & 1.0 & $8.34 \pm 0.02$ & $104 \pm 0.3$ \\
\hline & Billate processed tobacco leaves & $9.80 \pm 0.04$ & 1.0 & $10.8 \pm 0.08$ & $102 \pm 1$ \\
\hline & Nyala processed tobacco leaves & $8.95 \pm 0.31$ & 1.0 & $10.0 \pm 0.24$ & $107 \pm 3.1$ \\
\hline \multirow[t]{3}{*}{$\mathrm{Ni}$} & Shewa Robit raw tobacco leaves & $1.96 \pm 0.08$ & 0.6 & $2.49 \pm 0.02$ & $88.3 \pm 0.9$ \\
\hline & Billate processed tobacco leaves & $2.35 \pm 0.19$ & 0.6 & $2.91 \pm 0.08$ & $93.8 \pm 3.6$ \\
\hline & Nyala processed tobacco leaves & $4.70 \pm 0.04$ & 0.6 & $5.25 \pm 0.25$ & $91.7 \pm 6.1$ \\
\hline \multirow[t]{3}{*}{$\mathrm{Zn}$} & Shewa Robit raw tobacco leaves & $33.2 \pm 1.9$ & 1.4 & $34.6 \pm 0.25$ & $104 \pm 0.9$ \\
\hline & Billate processed tobacco leaves & $101 \pm 0.4$ & 1.4 & $103 \pm 0.4$ & $106 \pm 0.5$ \\
\hline & Nyala processed tobacco leaves & $79.3 \pm 0.77$ & 1.4 & $80.6 \pm 0.37$ & $94.3 \pm 0.6$ \\
\hline
\end{tabular}

Table 2 Metal concentration (mean \pm SD) in Ethiopian raw and processed tobacco leaves

\begin{tabular}{|c|c|c|c|c|c|c|}
\hline \multirow[t]{2}{*}{ Type of tobacco sample } & \multicolumn{6}{|c|}{ Concentration of metals $(\mu \mathrm{g} / \mathrm{g})$} \\
\hline & $\mathrm{Cd}$ & $\mathrm{Cu}$ & $\mathrm{Cr}$ & $\mathrm{Ni}$ & $\mathrm{Pb}$ & $\mathrm{Zn}$ \\
\hline Billate raw tobacco leaves & $1.20 \pm 0.05$ & $4.38 \pm 0.11$ & ND & ND & ND & $53.7 \pm 0.96$ \\
\hline Shewa Robit raw tobacco leaves & $1.30 \pm 0.04$ & $7.30 \pm 0.19$ & $1.45 \pm 0.11$ & $1.96 \pm 0.08$ & ND & $33.2 \pm 1.9$ \\
\hline Billate processed tobacco leaves & $1.45 \pm 0.02$ & $9.80 \pm 0.04$ & $1.65 \pm 0.08$ & $2.35 \pm 0.19$ & ND & $101 \pm 0.4$ \\
\hline Shewa Robit processed tobacco leaves & $1.90 \pm 0.05$ & $12.8 \pm 0.11$ & $1.75 \pm 0.08$ & $2.20 \pm 0.05$ & ND & $83.8 \pm 0.4$ \\
\hline Nyala processed tobacco leaves & $1.55 \pm 0.07$ & $8.95 \pm 0.31$ & $1.62 \pm 0.11$ & $4.70 \pm 0.04$ & ND & $79.3 \pm 0.77$ \\
\hline
\end{tabular}

ND not detected

abundance in the soil. Both areas of sampling were using phosphate fertilizer, which has significant contribution to metals concentration in tobacco leaves. Concentrations of other heavy metal in phosphate fertilizers vary considerably, depending on the phosphate rock source (Peuarossa et al. 1990).

In comparison to Billatte, Shewa Robit is more exposed to human activity and the farms were used for long time, which could have significant contribution to gradual accumulation of metals in tobacco farms through agricultural activities. This could be suggested as one of the reasons for the higher concentration of most metals determined in Shewa Robit than Billate. As indicated previously metals like $\mathrm{Ni}, \mathrm{Pb}$, and $\mathrm{Cr}$ in Billate leaves sample were below the detection limit of the instruments.

\section{Concentration of heavy metals in the processed tobacco leaves}

The average metal concentrations in processed tobacco leaves whose origin was from Billate were $\mathrm{Cd}$ (1.45), $\mathrm{Cu}$
(9.8), Ni (2.35), Cr (1.65), and Zn (101) $\mu \mathrm{g} / \mathrm{g}$ dry mass. The amounts of metals determined in the processed tobacco leaves whose origin was from Shewa Robit were $\mathrm{Cd}$ (1.9), Cu (12.8), Ni (2.2), Cr (1.75), Zn (83.8) $\mu \mathrm{g} / \mathrm{g}$ dry mass. In the same way $\mathrm{Cd}$ (1.55), $\mathrm{Cu}$ (8.95), $\mathrm{Cr}$ (1.62), Ni (4.7), Zn (79.3) $\mu \mathrm{g} / \mathrm{g}$ dry mass concentrations were found in Nyala (Table 2). Here large amount $\mathrm{Zn}$ was observed in processed tobacco sample collected from Billate in comparison to the others. The concentration of $\mathrm{Ni}$ was found to be higher in processed tobacco sample from Billate than the processed tobacco sample from Shewa Robit. In all the processed tobacco samples, the amount of $\mathrm{Pb}$ was found to be lower than the detection limit of the instruments.

Nyala type processed tobacco sample is different from other two processed tobacco in that it is the mixture of tobacco leaves from Shewa Robit and Billate, which account about 45-50 \%, and imported leaves from different country (Brazil, Zimbabwe, and India). In comparison to both processed samples from Billate and Shewa 
Robit higher $\mathrm{Ni}(4.7 \mu \mathrm{g} / \mathrm{g}$ dry mass) concentration was determined in Nyala sample. This concentration of $\mathrm{Ni}$ in Nyala could be suggested to come from tobacco leaves, which were imported.

\section{Comparison of metals in the raw tobacco leaves and processed tobacco samples}

The variation in composition of metals in the raw and processed tobacco leaves was observed for all the detected metals (Table 2).

This change in concentration of metals could be due to treatments and handling of tobacco leaves starting from harvesting to the cigarette manufacturing in the factory. During harvesting, transportation from the farm to the site of curing, transportation from site of curing to the factory and system of the storage could make leaves of tobacco be contaminated with dusts and soil, which contain these metals. The processes of packing and packing materials, curing system, treatments in the factory and chemical additives (casing activities) in the manufacturing, could have contribution for the contamination the tobacco leaves with the metals.

The other factor that made the large difference in concentration of metals could be: during the collection of tobacco leaves for analysis, in this study, the collected samples were washed with tape water and rinsed with distilled-deionized water. Since there is no such treatment in processed tobacco or in manufacturing of cigarette, the extraneous substances including soil and dust particles, and foliar spray residues could introduce extra metal contamination. Particularly tobacco leaves from the lower part were highly contaminated with soil. Therefore, metals from the soil that were deposited on the leaves could contribute to the high level of metals in the processed tobacco.

\section{Comparison of metals concentration in Ethiopian tobacco with literature values}

Many researchers have reported the concentration of metals in cigarette tobacco as well as tobacco leaves. Moulin et al. (2006) analyzed 755 tobacco's leaves samples during 2001-2003 and found that cadmium concentrations in the samples ranged from 0 to $6.78 \mu \mathrm{g} / \mathrm{g}$ dry mass. The report also indicated that $\mathrm{Cd}$ contents of flue cured tobacco leaves as India $(0.33 \pm 0.13)$, France $(1.46 \pm 1.35)$ and processed one from USA $(0.51 \pm 0.05)$ $\mu \mathrm{g} / \mathrm{g}$ dry mass.

There are also other literatures which reported the contents of some metals such as $\mathrm{Cu}$ (14.9-21.1), Zn (5184), Ni (<1 $\mu \mathrm{g} / \mathrm{g}$ dry mass), in flue cured tobacco leaves 24-33 $\mathrm{kg} / \mathrm{g}$ dry mass of $\mathrm{Zn}$ (Tso 1973); the concentration of nickel in cigarettes $(2.32-4.20 \mu \mathrm{g} / \mathrm{g}$ dry mass) and in tobacco leaves $(2.20-4.91 \mu \mathrm{g} / \mathrm{g}$ dry mass) (Stojanovic et al. 2004); the average concentration of $\mathrm{Cd}$ in both tobacco leaves and cigarettes in Mexican producedtobacco $(4.41 \pm 0.67$ and $2.65 \pm 0.99 \mu \mathrm{g} / \mathrm{g}$ dry mass respectively) (Saldivar et al. 1991).

As compared the report of Murty et al. (1986) (Table 3) the concentration of $\mathrm{Cd}$ in present study flue cured tobacco was higher than flue cured tobacco of India, New Zealand and within the range of other countries (America, Germany, and Canada) flue cured tobacco concentration. Generally the level of $\mathrm{Cd}$ in present study was within the range of the literature values, which can range from 0 to 6.78 (Moulin et al. 2006). However, in comparison with the flue-cured leaves from India and France, $\mathrm{Cd}$ content in present study was found to be higher than that of Indians' and lower than Frances' flue cured leaves (Moulin et al. 2006). The concentration of Ni in the present study was found to be within the range of literature value between 1 to $4.91 \mu \mathrm{g} / \mathrm{g}$ dry mass (Stojanovic et al. 2004; Tso 1973). The concentration of $\mathrm{Cu}$ is lower than the literature value which ranges from 14.9-21.14 $\mu \mathrm{g} / \mathrm{g}$. The level of $\mathrm{Zn}$ in the tobacco leaves in this study is also within the range of literature value, which ranges from 24 to $81 \mu \mathrm{g} / \mathrm{g}$ dry mass. Precise reported information was not obtained on the content of $\mathrm{Cr}$ in tobacco leaves from literatures.

There are also different reports of metal contents in processed tobacco from different countries, some of these are Vastarella et al. (2003), Ei-Amri et al. (1989), Zhang et al. (2005) and Nnorom et al. (2005) (Table 4).

As presented in Table 4 the Cd concentration of present study is within the range of minimum concentration determined in Japan's cigarette (Zhang et al. 2005) and maximum concentration obtained in the France cigarette

Table 3 Comparison of levels of $\mathrm{Cd}$ and $\mathrm{Pb}$ ( $\mu \mathrm{g} / \mathrm{g}$ dry mass) in Ethiopian raw tobacco leaves (present study) with literature values (Murty et al. 1986)

\begin{tabular}{lllllll}
\hline Metals & $\begin{array}{l}\text { Ethiopia } \\
\text { (present study) }\end{array}$ & India & America & Germany & New Zealand & Canada \\
\hline Cd & $1.20-1.30$ & $0.218-0.494$ & $1.7-2.9$ & $1.07-2.3$ & $0.23-0.56$ & $1.25-7.02$ \\
Lead & ND & $0.311-0.416$ & $0-200$ & $2.4-4.3$ & $0.48-0.55$ & $0.8-9.15$ \\
\hline
\end{tabular}

ND not detected 
Table 4 Comparison of metal concentration ( $\mu \mathrm{g} / \mathrm{g}$ dry mass) in the Ethiopian processed tobacco leaves (present study) with literature data (Zhang et al. 2005; Moulin et al. 2006; Ei-Amri et al. 1989)

\begin{tabular}{|c|c|c|c|c|c|c|c|c|c|c|}
\hline Metals & $\begin{array}{l}\text { Ethiopia } \\
\text { (mean, present study) }\end{array}$ & $\begin{array}{l}\text { Ethiopia } \\
\text { (Nyala, pre }\end{array}$ & ent study) & UK & France & Belgium & Italy & Germany & Japan & References \\
\hline $\mathrm{Cd}$ & 1.67 & 1.55 & & 1.62 & 1.59 & 1.22 & 1.96 & 1.96 & 1.04 & Zhang et al. (2005) \\
\hline $\mathrm{Ni}$ & 2.27 & 4.70 & & 5.62 & 8.91 & 9.44 & 8.60 & 9.11 & 3.24 & Zhang et al. (2005) \\
\hline $\mathrm{Pb}$ & ND & ND & & 14.3 & 15.6 & 14.7 & 22.0 & 17.2 & NR & Zhang et al. (2005) \\
\hline $\mathrm{Cr}$ & 1.70 & 1.62 & & 0.11 & 0.05 & 0.06 & 0.07 & 0.07 & NR & Zhang et al. (2005) \\
\hline $\mathrm{Zn}$ & 92.7 & 79.3 & & NR & NR & NR & $N R$ & NR & 75.8 & Zhang et al. (2005) \\
\hline Metal & Ethiopia (present study) & Cameroun & France & Germany & Switze & rland & UK & USA & & Reference \\
\hline $\mathrm{Cd}$ & $1.45-1.90$ & 1.30 & 2.30 & 1.80 & 1.27 & & 1.34 & 1.60 & & Moulin et al. (2006) \\
\hline Metals & Ethiopia (present study) & Libya & India & USA & Iran & \multicolumn{3}{|c|}{ Yugoslavia } & & References \\
\hline $\mathrm{Cr}$ & $1.62-1.75$ & $4.55-4.85$ & $3.0-8.2$ & $0.24-6.3$ & $4.3-6.2$ & \multicolumn{3}{|l|}{ NR } & & Ei-Amri et al. (1989) \\
\hline $\mathrm{Cu}$ & $8.95-12.8$ & $32.8-41.1$ & NR & NR & NR & \multicolumn{3}{|l|}{18.9} & & Ei-Amri et al. (1989) \\
\hline $\mathrm{Zn}$ & $79.3-101$ & $63.5-95.8$ & $15-31$ & $4.1-54$ & $51-56$ & \multicolumn{3}{|l|}{51} & & Ei-Amri et al. (1989) \\
\hline
\end{tabular}

$N D$ not detected, $N R$ not reported

(Zhang et al. 2005) (Table 4). The concentration of $\mathrm{Pb}$ obtained by this method is less than all the literature report. Similarly Ni in processed Shewa Robit and Billate is less than all other literature report. However, the $\mathrm{Ni}$ concentration determined in Nyala is within the range minimum report $(2.32 \mu \mathrm{g} / \mathrm{g})$ (Stojanovic et al. 2004) and maximum content of Germany's (9.11 $\mu \mathrm{g} / \mathrm{g}$ dry mass) cigarette (Saldivar et al. 1991).

Comparative results given Table 4 revealed that the $\mathrm{Zn}$ concentration in present study is found to be higher than the literature value. In contrast to $\mathrm{Zn}$, the amount of $\mathrm{Cu}$ is found to be lower than the literature values. The concentration of lead in present study is lower than its concentration in processed tobacco from other countries (Table 4). It has been demonstrated that most of the lead in green plant parts originate from deposition of air borne lead from automotive sources (Murty et al. 1986) and thus the lead content of tobacco leaves in this study can be expected to be low as such occurrences are minimum in Ethiopia. Even the lead in the soil is not in soluble form to be available to plant as compared to other metals.

In general, the concentrations of metals observed were more or less comparable with the reported literature values. However, relatively lower concentrations of $\mathrm{Cu}$ were observed in this study in comparison to the reported values.

\section{Conclusions}

An efficient digestion procedure was developed and validated through recovery studies. The optimal digestion procedure allowed the use of acids with minimum volumes leading to reduced blank concentration, and lowers the method detection limit. Furthermore, this condition allowed most elements determined with greater precision and accuracy.

This investigation revealed the dependence of metal accumulation in tobacco leaves on the geographical origin in which tobacco plant grows. The investigation has indicated the presence of heavy metals $(\mathrm{Cu}, \mathrm{Zn}, \mathrm{Cd}, \mathrm{Ni}$, $\mathrm{Cr}$ ), provided baseline data for comparison, give good awareness for general people (smokers and non-smokers), Ethiopian Tobacco Enterprise and Health Organizations. In addition, this study revealed comparability of the metal component of Ethiopian tobacco with other countries' tobacco. The concentrations of most of the metals detected are found to be within the range of literature values, except copper, which was found to be slightly lower than literature values. $\mathrm{Pb}$ was not detected in the Ethiopian tobacco leaves which make the Ethiopian tobacco free this toxic heavy metal.

Even though there is no industrial activity and no contaminated sewage sludge application in both the Ethiopian sample sites (Billate and Shewa Robit), the Cd concentration in Ethiopian tobacco was found to be comparable with industrialized countries and greater than that naturally available in the soil. Fertilizer could be the main contributor for such un-expected concentration of $\mathrm{Cd}$ in these un-industrialized and free of human impact sample sites.

This study revealed that there was large difference between the heavy metal content of raw tobacco leaves and processed tobacco. The large increment in composition of heavy metals in processed tobacco was observed for all the detected metals. This indicated that the metal contents that determined in cigarette are not only the content of raw leaves itself but also the metal originated from 
contamination of raw leaves during the process, starting from harvesting to cigarette manufacturing. Therefore, to control further contamination of tobacco leaves with toxic metals, well treatments in handling, transportation and storage of tobacco leaves are recommended.

\section{Author details}

${ }^{1}$ Department of Chemistry, College of Natural Sciences, Addis Ababa University, P.O. Box 1176, Addis Ababa, Ethiopia. ${ }^{2}$ Present Address: Department of Chemistry, Madawalabu University, P.O. Box 247, Robe, Bale, Ethiopia.

\section{Acknowledgements}

The authors are grateful to the Department of Chemistry, College of Natural Sciences, Addis Ababa University, Addis Ababa, Ethiopia for proving laboratory facilities and financial support. Girrma Regassa is thankful to Oromia Education Bureau, Ministry of Education, Ethiopia, for sponsoring his study.

\section{Authors' contributions}

BSC and GR contributed to design of the study. GR contributed to the sampling and analysis. GR and BSC contributed to the interpretation of data and drafting the manuscript. BSC contributed to critical revision of the paper. Both authors read and approved the final manuscript.

\section{Competing interests}

The authors declare that they have no competing interests.

\section{Funding}

This work was funded by Research and Graduate Programs of Addis Ababa University, Ethiopia. Research and Graduate Programs of Addis Ababa University, Ethiopia had no role in the design, data collection, analysis or publication of the manuscript.

Received: 22 November 2015 Accepted: 12 February 2016

Published online: 29 February 2016

\section{References}

Adeyeye El (2005) Trace metals in soil and plants from Fadama Farm in Ekitistat, Nigeria. Bull Chem Soc Ethiop 19:23-34

Ajab H, Yaqub A, Malik SA, Junaid M, Yasmeen S, Abdullah MA (2014) Characterization of toxic metals in tobacco, tobacco smoke, and cigarette ash from selected imported and local brands in Pakistan. Sci World J 2014:413614. doi:10.1155/2014/413614D

Angelova V, Ivanov K, Ivanova R (2004) Effect of chemical forms of lead, cadmium, and zinc in polluted soils on their uptake by tobacco. J Plant Nutr 27:757-773

Atlabachew M, Chandravanshi BS, Redi M (2010) Concentration levels of essential and non-essential metals in Ethiopian khat (Catha edulis Forsk). Biol Trace Elem Res 138:316-325

Atlabachew M, Chandravanshi BS, Redi M (2011) Profile of major, minor and toxic metals in soil and khat (Catha edulis Forsk) cultivars in Ethiopia. Trends Appl Sci Res 6:640-655

Baldwin DR, Marshall WJ (1999) Heavy metal poisoning and its laboratory investigation. Ann Clin Biochem 36:267-300

Bock R (1979) Decomposition method in analytical chemistry. The Blackie Group, Edinburgh

Campbell RCJ, Stephens WE, Meharg AA (2014) Consistency of arsenic speciation in global tobacco products with implications for health and regulation. Tob Induc Dis 12: 24, http://www.tobaccoinduceddiseases. com/content/12/1/24

Chang MJ, McDaniel RL, Naworal JD, Self DA (2002) A rapid method for the determination of mercury in mainstream cigarette smoke by two-stage amalgamation cold vapor atomic absorption spectrometry. J Anal At Spectrom 17:710-715

Ei-Amri FA, Saleh Al, Ei-Gnidy BA (1989) Determination of trace element concentrations of Libyan chewing and cigarette tobacco by instrumental neutron activation analysis. J Radioanal Chem 135:273-279
Eneji IS, Salawu OW, Sha'Ato R (2013) Analysis of heavy metals in selected cigarettes and tobacco leaves in Benue State, Nigeria. World J Med Med Sci Res 1:033-037

FAO (Food and Agricultural Organization) (1995) Country information brief, agricultural production and diversification programmes, review of food and cash crops production. Food and Agriculture Organization of the United Nations, Rome

FAO (Food and Agriculture Organization of the United Nations) (2003) Projections of tobacco production, consumption and trade to the year 2010. Food and Agriculture Organization of the United Nations, Rome

Gebre Selassie S, Gebre A (1996) Rapid assessment of drug abuse in Ethiopia, UNODC - Bulletin on Narcotics - 1996, Issue 1-004, pp 53-63

Geto A, Amare M, Tessema M, Admassie S (2012) Voltammetric determination of nicotine at poly(4-amino-3-hydroxynaphthalene sulfonic acid)-modified glassy carbon electrode. Electroanalysis 24:659-665

Golia EE, Dimirkou A, Mitsios IK (2008) Levels of heavy metals pollution in different types of soil of central Greece. Bull Environ Contam Toxicol 80:206-210

Grant CA, Buckley WT, Bailey LD, Selles F (1998) Cadmium accumulation in crops. Can J Plant Sci 78:1-17

Health Canada (1999) Determination of $\mathrm{Ni}, \mathrm{Pb}, \mathrm{Cd}, \mathrm{Cr}, \mathrm{As}$, Se and $\mathrm{Hg}$ in whole tobacco, tobacco control programme. Official Method, T-306, No. 1, pp $1-16$

lyengar GV, Subramanian KS, Woittiez JRW (1998) Elemental analysis of biological samples. CRC Press, Boca Rotan

Jarup L, Berglund M, Elinder CG, Nordberg G, Vahter M (1998) Health effects of cadmium exposure - a review of the literature and a risk estimate. Scand J Work Environ Health 24:1-51

Jones JB Jr, Wolf B, Mills H (1991) Plant analysis handbook. Micro-Macro Publishing, Athens

Kaličanin B, Velimirović D (2012) Potentiometric stripping analysis of zinc, cadmium and lead in tobacco leaves (Nicotiana Tabacum L.) and soil samples. Int J Electrochem Sci 7:313-323

Karaivazoglou NA, Tsotsolis NC, Tsadilas CD (2007) Influence of liming and form of nitrogen fertilizer on nutrient uptake, growth, yield, and quality of Virginia (flue-cured) tobacco. Field Crops Sci 100:52-60

Kassa H, Geto A, Admassie S (2013) Voltammetric determination of nicotine in cigarette tobacco at electrochemically activated glassy carbon electrode. Bull Chem Soc Ethiop 27:321-328

Kowalski R, Wierciński J (2009) Mercury content in smoke and tobacco from selected cigarette brands. Ecol Chem Eng S 16:151-162

Lazarević K, Nikolić D, Stošić L, Milutinović S, Videnović J, Bogdanović D (2012) Determination of lead and arsenic in tobacco and cigarettes: an important issue of public health. Cent Eur J Public Health 20:62-66

Lecours N, Almeida GEG, Abdallah JM, Novotny TE (2012) Environmental health impacts of tobacco farming: a review of the literature. Tobacco Control 21:191-196

Lugon-Moulin N, Ryan L, Donini P, Rossi L (2006) Cadmium content of phosphate fertilizers used for tobacco production. Agron Sustain Dev 26:151-155

Lugon-Moulin N, Martin F, Krauss MR, Ramey PB, Rossi L (2008) Arsenic concentration in tobacco leaves: a study on three commercially important tobacco (Nicotiana tabacum L.) types. Water Air Soil Pollut 192:315-319

Maier QEA, Griepink B (1995) Quality assurance for environmental analysis. Elsevier, Amsterdam

Maruyama Y, Komiya K (1973) Determination of copper, arsenic and mercury in tobacco leaves by neutron activation analysis. Radioisotopes 22:572-574

Miller JN, Miller JC (2000) Statistics and chemometrics for analytical chemistry, 4th edn. Pearson Practice Hall, England

Moulin N, Martin F, Krauss F, Ramey PB, Rossi L (2006) Cadmium concentration in tobacco from different countries and its relationship with other elements. Chemosphere 63:1074-1086

Murty KSN, Tjell JC, Gopalachari NC (1986) Lead and cadmium content of Indian flue-cured tobacco. Plant Soil 95:281-284

National Tobacco Enterprise (NTE) (2006) Draft of strategic plan of National Tobacco Enterprise (NTE). National Tobacco Enterprise (NTE), Addis Ababa

Nnorom IC, Osibanjo O, Oji-nnorom CG (2005) Cadmium determination in cigarettes available in Nigeria. Afr J Biotechnol 4:1128-1132

Nordberg G, Nogawa K, Nordberg M, Friberg L (2007) Handbook on toxicology of metals. Academic Press, New York 
Peuarossa BF, Malorgio L, Lubrano F, Petnine G (1990) Phosphatic fertilizers as source of heavy metals in protected cultivation. Commun Soil Sci Plant Anal 21:737-751

Piadé J-J, Jaccard G, Dolka C, Belushkin M, Wajrock S (2015) Differences in cadmium transfer from tobacco to cigarette smoke, compared to arsenic or lead. Toxicol Rep 2:12-26

Rothwell K, Yorkshire K (1999) Health effects of interactions between tobacco uses and exposure to other agents. World Health Organization, Geneva

Saldivar L, Luna M, Reyes E, Soto R (1991) Cadmium determination in Mexicanproduced tobacco. Environ Res 55:91-96

Sharma P, Dubey RS (2005) Lead toxicity in plants. Braz J Plant Physiol 17:35-52

Smith CJ, Doolittle DJ (1999) An international literature survey of "IARC Group I Carcinogens" reported in mainstream cigarette smoke. Food Chem Toxicol 37:265-266

Stojanovic D, Nikic D, Lazarevic K (2004) The level of nickel in smoker's blood and urine. Cent Eur J Public Health 12:187-189

Suzuki T, Shishido S, Urushiyama K (1976) Mercury in cigarettes. Tohoku J Exp Med 119:353-356

Taebunpakul S, Liu C, Wright C, MCAdam K, Heroult J, Braybrook J, GoenagaInfante H (2011) Determination of total arsenic and arsenic speciation in tobacco products: from tobacco leaf and cigarette smoke. J Anal At Spectrom 26:1633-1640
Tassew Z, Chandravanshi BS (2015) Levels of nicotine in Ethiopian tobacco leaves. SpringerPlus 4:649. doi:10.1186/s40064-015-1448-y

Tso TC (1973) Physiology and biochemistry of tobacco plant. Department of Agriculture, Plant Science Research Division, Mary Land

Vastarella W, Mola M, Caputi M (2003) Determination of trace metals in main and sidestream smoke by ICP-AEP: a procedure for recovery and analysis. Annual report about the Research Project, Napoli, Italian Tobacco Agency

Verma S, Yadav S, Singh I (2010) Trace metal concentration in different Indian tobacco products and related health implications. Food Chem Toxicol 48:2291-2297

Zerihun A, Chandravanshi BS, Debebe A, Mehari B (2015) Levels of selected metals in leaves of Cannabis sativa L. cultivated in Ethiopia. SpringerPlus 4(1):359. doi:10.1186/s40064-015-1145-x

Zhang C, Miura J, Nagoas Y (2005) Determination of cadmium, zinc, nickel and cobalt in tobacco by reversed-phase high-performance liquid chromatography with 2-(8-quinolylazo)-4,5-di phenylimidazole as chelating reagent. Anal Sci 21:1105-1110

Zhangyu C, Yang G-Y, Shuhua W, Ling L, Qingde S (2004) Simultaneous determination of tin, nickel, lead and mercury in tobacco and tobacco additives by microwave digestion and RP-HPLC followed by on-line column enrichment. J Chin Chem Soc 51:71-77

\section{Submit your manuscript to a SpringerOpen ${ }^{\odot}$ journal and benefit from:}

- Convenient online submission

- Rigorous peer review

- Immediate publication on acceptance

- Open access: articles freely available online

- High visibility within the field

- Retaining the copyright to your article

Submit your next manuscript at $>$ springeropen.com 